\title{
BMJ Open How does age-related macular degeneration affect real-world visual ability and quality of life? A systematic review
}

\author{
Deanna J Taylor, Angharad E Hobby, Alison M Binns, David P Crabb
}

To cite: Taylor DJ, Hobby AE, Binns AM, et al. How does age-related macular degeneration affect real-world visual ability and quality of life? A systematic review. BMJ Open 2016;6:e011504. doi:10.1136/bmjopen-2016011504

- Prepublication history and additional material is available. To view please visit the journal (http://dx.doi.org/ 10.1136/bmjopen-2016011504).

Received 12 February 2016 Revised 21 September 2016 Accepted 4 November 2016

CrossMark

Division of Optometry and Visual Science, School of Health Sciences, City, University of London, London, UK

Correspondence to Professor David P Crabb; David.Crabb.1@city.ac.uk

\section{ABSTRACT}

Objectives: To review systematically the evidence of age-related macular degeneration (AMD) affecting realworld visual ability and quality of life (QoL). To explore trends in specific topics within this body of the literature.

Design: Systematic review.

Methods: A systematic literature search was carried out using MEDLINE, EMBASE, CINAHL, PsycINFO,

PsychARTICLES and Health and Psychosocial

Instruments for articles published up to January 2015 for studies including people diagnosed with AMD, assessing real-world visual ability or QoL as an outcome. Two researchers screened studies for eligibility. Details of eligible studies including study design, characteristics of study population and outcomes measured were recorded in a data extraction table. All included studies underwent quality appraisal using the Mixed Methods Appraisal Tool 2011 Version (MMAT).

Results: From 5284 studies, 123 were eligible for inclusion. A range of approaches were identified, including performance-based methods, quantitative and qualitative patient-reported outcome measures (PROMs). AMD negatively affects tasks including mobility, face recognition, perception of scenes, computer use, meal preparation, shopping, cleaning, watching TV, reading, driving and, in some cases, self-care. There is evidence for higher rates of depression among people with AMD than among community dwelling elderly. A number of adaptation strategies have been associated with AMD of varying duration. Much of the research fails to report the type of AMD studied ( $59 \%$ of included studies) or the duration of disease in participants (74\%). Of those that do report type studied, the breakdown is as follows: wet AMD 20\%, dry AMD 4\% and both types 17\%.

Conclusions: There are many publications highlighting the negative effects of AMD in various domains of life. Future research should focus on delivering some of this research knowledge into patient management and clinical trials and differentiating between the types of AMD.

\section{INTRODUCTION}

Age-related macular degeneration (AMD) is a highly prevalent condition which causes loss of central vision. ${ }^{1}$ It is the most common cause of blindness in developed countries

\section{Strengths and limitations of this study}

- This is the first systematic review to include patient-reported and performance-based outcome measures in this field.

- The most recent systematic reviews in this field were published almost 10 years ago.

- Studies about the effect of age-related macular degeneration (AMD) on reading were not included as this is a topic that is already well reported on.

- A large proportion of included studies did not report type of $A M D$ investigated or duration of AMD.

and is labelled a 'priority eye disease' by the WHO. $^{2}$ In the UK, an incidence of 71000 new cases of late AMD per year has been estimated. ${ }^{3}$ Incidence and prevalence are set to rise as the population ages. ${ }^{4}$

AMD can be divided into early and late stages. The early stage, also referred to as age-related maculopathy (ARM), is characterised by yellow/white deposits (drusen) beneath the retinal pigment epithelium, and areas of hyperpigmentation or hypopigmentation. ${ }^{5}$ Later stages may take one of two forms: neovascular (wet or exudative) AMD (nAMD), characterised by growth of new blood vessels beneath the retina with a tendency to leak, causing sudden vision loss, or geographic atrophy (GA, dry AMD), characterised by sharply demarcated areas of hypopigmentation in which choroidal blood vessels are more visible than in surrounding areas, causing more insidious vision loss. ${ }^{5} 7$

Quality of life (QoL) is a subjective measure $^{8} 9$ influenced by factors including expectations, relationships, ${ }^{10}$ routine, ${ }^{11}$ health and disability. ${ }^{12}$ QoL is often used interchangeably with health status, functional status and health-related quality of life, ${ }^{13}{ }^{14}$ although there are subtle differences 
between each of these ${ }^{15}$ (see table 1). For the purpose of this article, we use QoL to encompass these slightly different terms.

QoL is often measured using patient-reported outcome measures (PROMs), normally via a questionnaire. ${ }^{16} 17$ This allows 'a better understanding of the relationship between the pathophysiology of eye disease and patient-reported functioning' ${ }^{18}$ Performance-based measures are another type of tool for assessing functional ability or disability. Results from PROMs and performance-based measures may differ, but this review will consider both. ${ }^{19-21}$

As AMD incidence increases, it is important to understand how it affects visual function and QoL. Previous large-scale systematic reviews, the most recent published a decade ago, ${ }^{22} 23$ concentrate on PROMs and do not describe real-world performance-based measures. More recent systematic reviews ${ }^{24-28}$ are much smaller scale, concentrating on only one aspect of patients' experiences with AMD, and again, do not consider performance-based measures. Progress in this field could be an important step towards designing appropriate strategies for monitoring disease progression, rehabilitation, justification of new treatments and designing more meaningful outcomes for clinical trials.

This systematic review investigates the effect of AMD on visual disability and QoL and explores trends in specific topics within this body of literature.

\section{METHODS}

A search of the electronic databases MEDLINE, EMBASE, CINAHL, PsycINFO, PsychARTICLES and Health and Psychosocial Instruments was undertaken using keywords relating to AMD, QoL and real-world visual disability (see online supplementary appendix 1 for a detailed breakdown of search terms).

Retrospective and prospective reference list searches were conducted for studies meeting eligibility criteria and relevant reviews. Eligible studies involved people diagnosed with AMD, considered an aspect of real-world visual ability or QoL as an outcome, were available in English and involved human participants only. Studies were excluded if they only considered standard clinical measures of visual function. They were also excluded if outcomes were a result of an intervention or treatment (including clinical trials) or if an abstract only was published (conference proceedings). Review articles were excluded. Two authors (DJT and AEH) screened studies to assess eligibility. In the case of disagreements unresolved through discussion, a third author (DPC) was consulted. Owing to the extensive body of literature and existing reviews ${ }^{29}{ }^{30}$ concerning the impact of AMD on reading, studies concerning this were excluded.

Relevant information (including study design, study population characteristics and outcomes measured) from eligible papers was entered into a data extraction table.

Quality appraisal was conducted using the Mixed Methods Appraisal Tool 2011 Version (MMAT) ${ }^{31}$ This is a recently developed but increasingly recognised tool, with over 90 citations in the literature, including a number of high-quality systematic reviews. ${ }^{32-34}$ This tool was chosen for this study because it facilitates methodological appraisal of quantitative, qualitative and mixed methods studies. Scores are based on meeting criteria, which differ according to study type. For each criterion met, a score of 1 is given, up to a possible total of 4 for each study. Criteria which are not met, or those for which information is not given in the study, a score of 0 is given. Full details of grading criteria are shown in table 2.

\section{RESULTS}

The search was conducted on 6 January 2015 yielding 5712 results. An additional 15 studies were identified for inclusion from reference lists of relevant primary studies and reviews. Reviewers were in agreement for 5045/5269 $(95.7 \%)$ of records. Discrepancies were resolved as described previously. A total of 123 studies were selected for inclusion. Online supplementary appendix 2 summarises the characteristics and outcomes of these studies. Many studies were excluded at the record screening stage. The main reasons for this were that they did not report outcomes relating to QoL or real-world visual ability or did not include participants with AMD. Details of assessment of articles for eligibility along with reasons for excluding full-text articles are shown in figure 1 .

All 123 included studies underwent methodological quality appraisal using the Mixed Methods Appraisal

Table 1 Definitions of selected terms related to quality of life (adapted from Patrick et al ${ }^{15}$ )

\begin{tabular}{ll}
\hline Term & Definition \\
\hline Functional status & $\begin{array}{l}\text { An individual's effective ability to perform valued roles, tasks or activities (eg, going to work, } \\
\text { playing sports or housework). }\end{array}$ \\
$\begin{array}{l}\text { Pealth-related quality of life } \\
\text { (HRQL) }\end{array}$ & $\begin{array}{l}\text { sersonal health status. HRQoL usually refers to aspects of our lives that are dominated or } \\
\text { suality of life (QoL) }\end{array}$ \\
$\begin{array}{l}\text { An evaluation of all aspects of our lives, including, for example, where we live, how we live } \\
\text { and how we play, encompassing life factors such as family circumstances, finances, housing } \\
\text { and job satisfaction. }\end{array}$ \\
Well-being & $\begin{array}{l}\text { Subjective bodily and emotional states; how an individual feels; a state of mind distinct from } \\
\text { functioning that pertains to behaviours and activities. }\end{array}$ \\
\hline
\end{tabular}


Table 2 MMAT grading criteria (adapted from Pace et $a{ }^{\beta 1}$ )

\section{Types of mixed methods study components or primary studies}

Screening questions (for all types)

1. Qualitative

2. Quantitative randomised control (trials)

3. Quantitative non-randomised

\section{Methodological quality criteria}

(See tutorial for definitions and examples)

Are there clear qualitative and quantitative research questions (or objectives), or a clear mixed methods question (or objective)?

Do the collected data allow address the research question (objective)? Eg.

Consider whether the follow-up period is long enough for the outcome to occur (for longitudinal studies or study components).

Further appraisal may not be feasible or appropriate when the answer is 'No' or 'Can't tell' to one or both screening questions

1.1 Are the sources of qualitative data (archives/documents/informants/ observations) relevant to address the research question (objective)?

1.2 Is the process for analysing qualitative data relevant to address the research question (objective)?

1.3 I appropriate consideration given to how findings relate to the context, eg the setting, in which the data were collected?

1.4 Is appropriate consideration given to how findings relate to researchers' influence, eg through their interactions with participants?

2.1 Is there a clear description of the randomisation (or an appropriate sequence generation)?

2.2 Is there a clear description of the allocation concealment (or blinding where applicable)?

2.3 Are there complete outcome data?

2.4 Is there low withdrawal/drop-out (below 20\%)?

3.1 Are participants (organisations) recruited in a way that minimises selection bias?

3.2 Are measurements appropriate (clear origin, or validity known, or standard instrument; and absence of contamination between groups when appropriate) regarding the exposure/intervention and outcomes?

3.3 In the groups being compared (exposed vs non-exposed; with intervention vs without; cases vs controls), are the participants comparable, or do researchers take into account (control for) the difference between these groups?

3.4 Are there complete outcome data ( $80 \%$ or above), and, when applicable, an acceptable response rate ( $60 \%$ or above), or an acceptable follow-up rate for cohort studies (depending on the duration of follow-up)?

4.1 Is the sampling strategy relevant to address the quantitative research question (quantitative aspect of the mixed methods question)?

4.2 Is the sample representative of the population understudy?

4.3 Are measurements appropriate (clear origin, or validity known, or standard instrument)?

4.4 Is there an acceptable response rate (60\% or above)?

5.1 Is the mixed methods research design relevant to address the qualitative and quantitative research questions (or objectives), or the qualitative and quantitative aspects of the mixed methods question (or objective)?

5.2 Is the integration of qualitative and quantitative data (or results) relevant to address the research question (objective)?

5.3 Is appropriate consideration given to the limitations associated with this integration, eg the divergence of qualitative and quantitative data (or results) in a triangulation design?

Criteria for the qualitative component (1.1 to 1.4), and appropriate criteria for the quantitative component (2.1 to 2.4 , or 3.1 to 3.4 , or 4.1 to 4.4 ), must be also applied).

MMAT, Mixed Methods Appraisal Tool.

Tool 2011 Version (MMAT). ${ }^{31}$ Eleven studies (9\%) had a score of 2, $33(27 \%)$ scored 3 and the remaining 79 $(64 \%)$ had a score of 4 . Most frequent sources of bias were related to groups not being comparable and differences between groups not being accounted for, followed by issues regarding recruitment and sample size. Online supplementary appendix 3 shows details of quality appraisal for all included studies. 


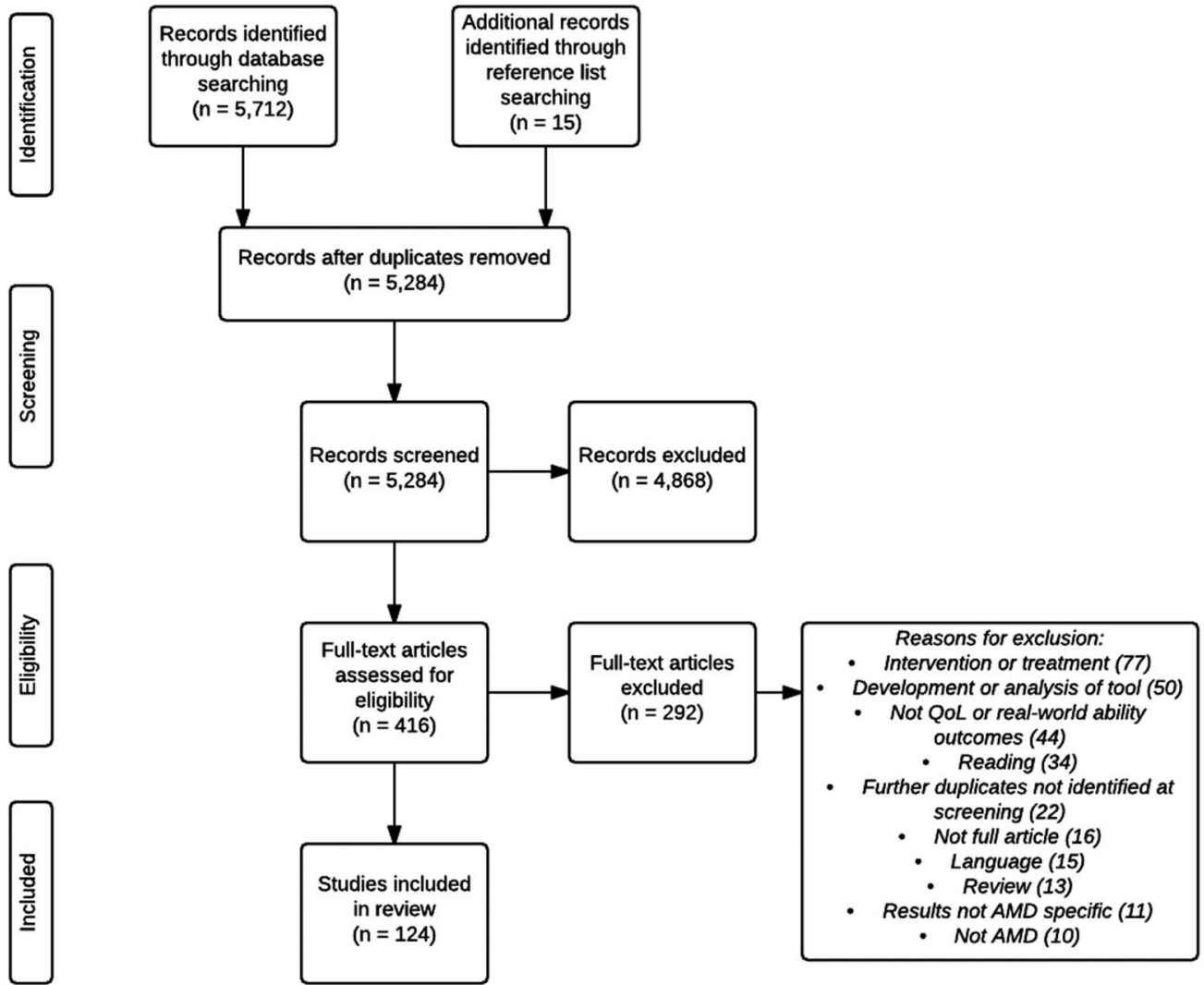

Figure 1 Study selection process.

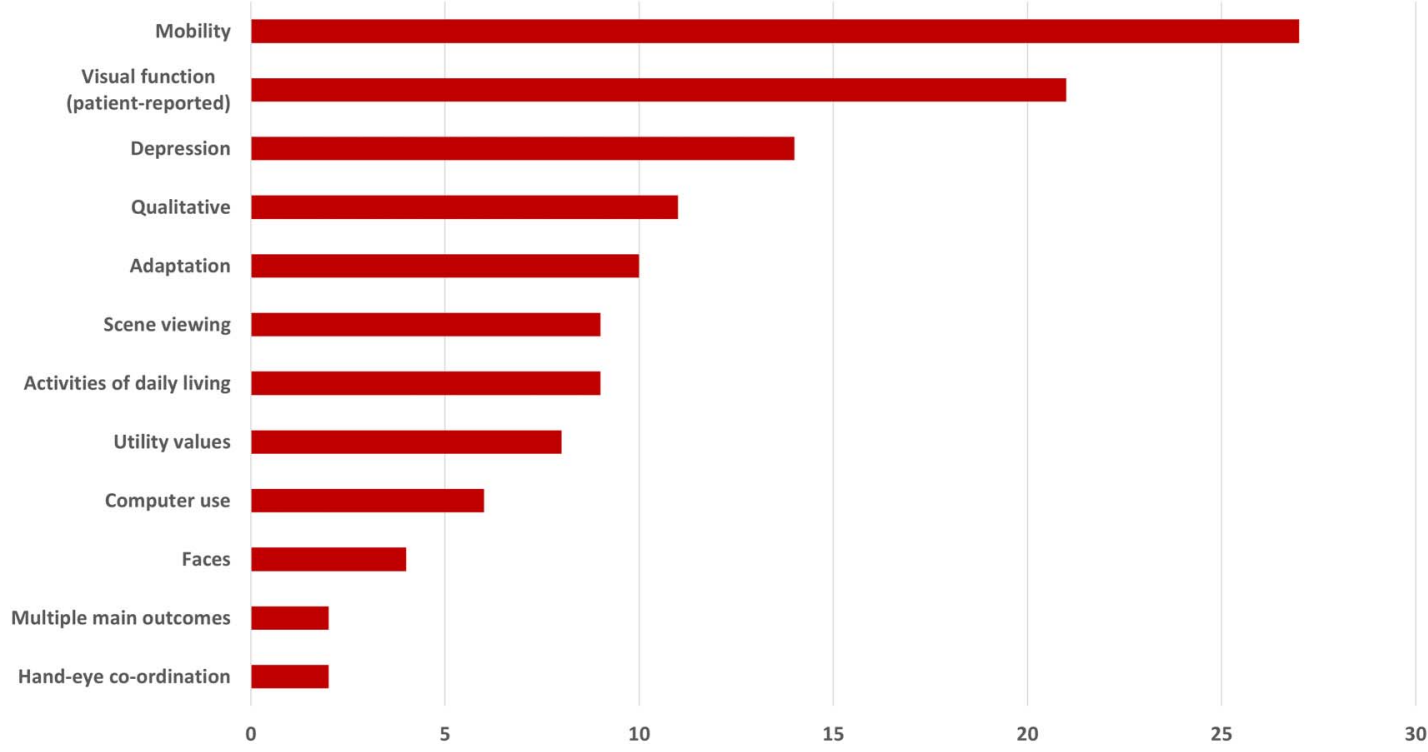

Figure 2 Domains of QoL and real-world visual ability covered by included studies.

Below is a short description of the main findings of studies included in the systematic review. For further details of the studies, including experimental design and sample sizes, see online supplementary appendix 2 . The overview of the study findings is organised according to the outcome main dimension. Figure 2 shows the wide range of domains reported by studies included in this review, the most frequent of which are mobility (22\% of studies) and patient-reported visual function $(17 \%)$. 


\section{Performance-based studies}

\section{Mobility}

Twenty-one studies, including 1131 people with AMD, investigating the effect of AMD on mobility performance were identified. The majority of these $(n=14)$ were casecontrol studies, followed by cross-sectional studies $(n=5)$, along with one cohort study and one longitudinal study.

\section{Basic mobility}

Individuals with AMD have been found to travel less and be less likely to drive than those with other eye diseases. ${ }^{35}$ They are reported to have poorer balance and postural stability than non-AMD participants under a range of conditions. ${ }^{36-38}$ Binocular central scotoma size was a predictor of mobility performance in an obstacle course for people with AMD. ${ }^{39}$

\section{Road crossing}

People with AMD were equally able to detect traffic gaps when crossing roads, but with a longer delay, reducing safety margins compared with fully sighted controls and those with peripheral vision loss. ${ }^{40}$ People with AMD fixated primarily on vehicles rather than traffic lights while waiting to cross, ${ }^{41}$ and they have been shown to make fewer head turns shortly before road crossing, preventing up-to-date road status information being gathered. ${ }^{42}$ Overall, however, people with AMD were similar to age-related controls in accuracy and precision of their road crossing decisions. ${ }^{43}$

\section{Travel patterns}

A uniquely designed case-control study investigated travel patterns using a cellular tracking device. ${ }^{44}$ Among 65 participants with AMD, average excursion distance and span of travel reduced with visual acuity (VA) loss.

\section{Driving skills}

One case-control study ${ }^{45}$ compared detection of traffic signals in four small groups of volunteers: young and elderly visually healthy, ARM ( $\mathrm{n}=8$, with depressed VA, fundus changes such as drusen and pigmentary changes, some central field defects and colour vision defects) and preARM $(n=10$, defined as normal VA with macular drusen and/or pigment changes). ARM patients had slower reaction times. Interestingly, the preARM group had results outside the limits set by controls, implying that real-world tasks may be affected before clinically measured function. Another case-control study ${ }^{46}$ showed 10 AMD patients to perform worse than controls on an interactive driving simulator and an on-road driving test.

\section{Effect of lighting conditions}

Six studies assessed mobility under different lighting conditions. ${ }^{4-52}$ People with AMD walked slowly and cautiously during light and dark adaptation, while fully sighted people only behaved in this way during dark adaptation, indicating that those with healthy vision respond during dark adaptation as though their vision were impaired. ${ }^{48}$
People with AMD walk more cautiously, make more gait modifications while walking on altered surfaces ${ }^{47}$ and have difficulty stepping on low contrast targets in dim light and during dark adaptation. ${ }^{49}$ AMD affects navigating paths under low lighting ${ }^{51}$ and curb navigation particularly during dim lighting and dark adaptation. ${ }^{50}$ AMD patients performed worse on an obstacle course in dim lighting compared to well-lit conditions. ${ }^{52}$

\section{Falls and miscellaneous}

Two cross-sectional studies found that individuals with AMD have greater falls risk than those without ${ }^{53}$ and that fear of falling results in activity limitation. ${ }^{54}$ One case-control study ${ }^{55}$ used eye tracking and audio feedback while participants watched video simulations of walking through a building: AMD volunteers made more comments and more fixations than controls.

\section{Faces}

Five studies (four case-control and one cross-sectional) including 171 people with AMD, investigating the effect of AMD on viewing faces were identified.

These studies cover a range of outcomes including familiar face recognition, facial expression discrimination and eye movements while viewing an image of a face in people with AMD. ${ }^{56-60}$ AMD patients performed better at detecting whether a face had an expression or not than on categorising the expression. ${ }^{57}$ In one casecontrol study, ${ }^{56}$ only $26 \%$ of a group of 100 AMD patients correctly identified the facial expression on all four photographs shown. Familiar face recognition and facial expression detection performance has been estimated to worsen with reduced luminance. ${ }^{58}$ One study reported significant differences in eye movements made by nine people with AMD compared to nine controls. ${ }^{59}$ Another indicated perceived disability in face recognition to not correlate with actual face recognition performance. ${ }^{60}$

\section{Scene viewing}

Nine studies investigating the effect of AMD on scene viewing were identified. These included a total of 176 participants with AMD. These were all case-control studies.

People with AMD are reported to recognise isolated objects better than objects in scenes, coloured images better than achromatic images, ${ }^{61}$ recognise an object in a scene more easily when enhanced with a border ${ }^{62}$ and when placed on a related compared to an unrelated background. ${ }^{63}$ AMD has been shown to affect processing of high-spatial frequency scenes. ${ }^{64}$ Moreover, images have been shown to be more recognisable for AMD patients at lower spatial frequency bandwidths if the background is darkened. ${ }^{65}$ One study asking participants whether or not a real-world target was present in a scene at varying levels of contrast found task success to be strongly related to contrast level. ${ }^{66}$ 
People with AMD have been reported to categorise scenes as natural versus urban faster and more accurately than indoor versus outdoor, while no differences were found between these conditions for visually healthy people. ${ }^{67}$ In another study, participants undertook a natural versus urban scene categorisation task in which images were randomly presented in one of five locations on the computer screen. ${ }^{68}$ While controls performed better when the image was presented centrally compared with peripheral presentation, AMD patients performed worse at all locations than controls and did not perform better for central than peripheral presentations.

In another experiment, ${ }^{69}$ participants were presented with a view of a scene (the prime view) and asked to change the viewpoint in a computer program representing the scene, until the viewpoint matched the prime view. Controls $(n=13)$ and AMD patients $(n=19)$ had bias towards 'middle views' of a scene; this was more pronounced in AMD patients. Authors hypothesised that disruption to central vision causes incorrect scene perception.

\section{Computer use}

Six studies investigating the effect of AMD on computer use were identified. These included a total of 57 participants with AMD. Four of these were case-control studies, while two were case series.

AMD may result in difficulty using computers. ${ }^{70-75}$ Performance in a simple task involving identification of commonly used computer icons was significantly associated with worsening VA, contrast sensitivity (CS) and colour vision defects in 18 people with AMD. ${ }^{73}$ Other studies found that performance could also be affected by features of the graphical user interface, ${ }^{70} 717475$ although all but one ${ }^{73}$ of these studies investigated only six or less people with AMD. Patients with dry AMD have been shown to benefit from auditory and haptic feedback when performing computer-based tasks. ${ }^{72}$

\section{Other tasks}

In a case-control study of 100 people with AMD (92 with nAMD), $48 \%$ were able to tell the time from a boldfaced wall clock $1.5 \mathrm{~m}$ away, $70 \%$ correctly identified the colour of four handkerchiefs coloured red, blue, tan and grey, and $68 \%$ correctly identified four commonly used household products when presented with wellknown brands of cereal, tomato ketchup, dish detergent and milk. ${ }^{56}$ Differences between people with $(\mathrm{n}=10)$ and without $(\mathrm{n}=10)$ AMD have been reported in a casecontrol study investigating performance of reach-to-grasp tasks. ${ }^{76}$ A further case-control study ${ }^{77}$ reported that poor handwriting legibility in eight patients with scotoma caused by AMD may be a result of difficulty placing letters in the correct location due to inability to view the writing area.

\section{Patient-reported outcomes}

\section{Patient-reported visual function}

Twenty-two studies investigating the effect of AMD on patient-reported general visual function were identified. These included a total of 10877 participants with AMD. Twenty of these were cross-sectional studies and two were cohort studies.

The National Eye Institute Vision Function Questionnaire (NEI-VFQ) is a widely used PROM in AMD. ${ }^{23}$ Average scores are reported to be poorer in people with AMD compared to those without ${ }^{16} \quad 78-84$ and, unsurprisingly, worse in more severe disease. ${ }^{16} 83-85$ Results from studies using different tools are mostly aligned with these findings. ${ }^{86-90}$ A prospective longitudinal study investigating change in visual function in 671 women with AMD over a 5-year period found worse NEI-VFQ scores in those with late AMD at the beginning and end of the study compared to those progressing from early to late AMD. ${ }^{91}$ Two large-scale cross-sectional studies investigating 2194 and 1052 people with AMD found no association ${ }^{84}$ and weak association ${ }^{92}$ with early AMD, respectively, although a smaller study $(n=106)$ using a different PROM did find impaired visual function in those with mild AMD. ${ }^{88}$ Best and worst eye VA were found to contribute independently to NEI-VFQ scores. ${ }^{193}$ NEI-VFQ scores were worse in individuals with binocular compared to monocular visual loss from AMD, ${ }^{94} 95$ although 54 patients with blindness in one eye reported greater emotional distress than 54 with binocular blindness, perhaps due to uncertainty regarding future disease progression. ${ }^{96}$ Interestingly, patients with high response on a neuroticism scale reported worse visual function than those with average response, regardless of VA. ${ }^{97}$

\section{Mobility}

Seven studies investigating the effect of AMD on patientreported mobility were identified. These included a total of 655 participants with AMD. Four of these were crosssectional, two were cohort studies and one was a longitudinal study.

Two separate retrospective studies have reported lower rates of motor vehicle collision among people with AMD compared to matched controls. ${ }^{46} 98$ These and other studies concluded that AMD patients self-regulate by changing driving habits, for example, avoiding driving at night, in unfamiliar areas or over long distances. ${ }^{99} 100$

Higher self-reported fall rates have been reported among AMD patients compared with those without. ${ }^{78-80}$ Among AMD patients, reduced CS and VA have been associated with more self-reported falls (using diaries). ${ }^{101}$ Older women with AMD have been reported to have almost twice the risk of injurious falls (selfreported) than those without. ${ }^{102}$ AMD has been associated with fear of falling, ${ }^{103}$ and another PROM-based cross-sectional study concluded that limited life space and activities due to fear of falling seem to mediate the relationship between eye disease and depression. ${ }^{104}$ 


\section{Utility values}

Eight cross-sectional studies investigating the effect of AMD on utility values were identified. These included a total of 1768 participants with AMD.

Utility values, a type of PROM, give quantitative expressions of preference for given health states ${ }^{23}$ and can be assessed using different methods. For example, standard gamble ascertains risk people would be willing to take in order not to have a certain health condition and the time trade off hypothetically assesses life years sacrificed in order to avoid the condition. Scores are normally presented on a scale between 0 and 1; higher scores indicate better health or less willing to take risks to avoid a condition. Average values for AMD range from 0.60 to $0.81 ;^{105-107}$ patients with worse vision loss from AMD score lower than those with mild loss. ${ }^{105} \mathrm{~A}$ different utility value scale yielded mean preference values for nAMD patients of 0.62 to $0.64 .{ }^{108}$ Utility values allow comparisons between different health conditions. Values for AMD are comparable with asymptomatic HIV (0.69), mild osteoarthritis of the hip (0.69), mild and moderate angina (0.88 and 0.83$)$, mild and moderate myocardial infarction $(0.91$ and 0.80$)$ and diabetes mellitus (0.88). ${ }^{109}$ Values reported for other eye diseases include glaucoma (0.64 to 1.0$)$ and diabetic retinopathy $(0.59$ to 0.94$) .{ }^{110}$ One cross-sectional study ${ }^{111}$ compared utility values between AMD and diabetic retinopathy and found comparable values for equivalent levels of VA loss in each disease. Another cross-sectional study ${ }^{112}$ found CS to be a good predictor of utility values in 209 AMD patients.

Utility values are often established from members of the public who are given descriptions of the health condition being assessed; these tend to yield higher values than those from people with AMD. ${ }^{113}$ This is supported by results of other studies ${ }^{114}{ }^{115}$ using time trade off scores which showed utility values were consistently overestimated by the public, non-ophthalmic and even ophthalmologists when compared to ratings by AMD patients themselves. ${ }^{114} 115$ It may be impossible to appreciate the consequences of vision loss without having experienced them. ${ }^{114}$

\section{Depression}

Fourteen studies investigating the effect of AMD on depression were identified. These included a total of 1880 participants with AMD. Eight of these were crosssectional, two were cohort studies, one was longitudinal and one was a case report.

Associations between levels of depression and AMD have been reported in the literature. ${ }^{104}$ Estimated prevalence rates for depression range from $11 \%$ to $44 \%$ among AMD patients, ${ }^{116-119}$ the highest of these figures is two to three times the rate found for elderly controls. In contrast, one cross-sectional study ${ }^{120}$ found no association between AMD and depression. Differences between results may arise from different tools used to assess depression in these studies and different recruitment methods (clinic-based vs population/community-based sample). Selective mortality and limiting eligibility criteria have also been suggested as reasons for not finding an association in some studies. ${ }^{120}$ Depression in AMD has been reported to be strongly correlated with increasing VA loss ${ }^{121}$ and is predicted by neurotic personality. ${ }^{122}$ In other studies depressive symptoms, even if minimal, were associated with loss of visual function regardless of VA level. ${ }^{122-127}$ AMD patients $(\mathrm{n}=144)$ who reported poor adaptation to vision loss, especially with respect to acceptance of and compensation for vision loss, reported more depressive symptoms than those who adapted better. ${ }^{128}$ One case report highlights risk of suicide because of AMD-related vision loss; ${ }^{129}$ eye-care providers should be trained to identify patients at risk of suicidality.

\section{Adaptation}

Fourteen studies investigating adaptation to AMD were identified. These included a total of 1122 participants with AMD. Two of these were case-control, one was a cohort study, four were longitudinal and three were cross-sectional.

Studies have investigated adaptation to AMD based on Heckhausen and Schulz life-span theory of control. ${ }^{130}{ }^{131}$ Usage of internal resources (such as time and effort) was positively associated with ability to carry out activities of daily living, and external resource finding (such as using low vision services and aids) and increase of motivational commitment were positively associated with positive emotion. ${ }^{131}{ }^{132}$ External resource finding increased shortly after diagnosis, perhaps as patients initially sought advice and support. ${ }^{133}$ Internal resource usage and motivational input have been found to decrease over time in AMD patients, while external resource finding and replacement of desired goals partially increased over this time. ${ }^{134}$ External resource finding ${ }^{135}$ and replacement of desired goals ${ }^{133}$ increased as patients lost ability to carry out activities of daily living. Variations in coping strategies, along with cognitive ability, have been reported to influence self-report of visual function. ${ }^{136}$

One longitudinal study ${ }^{137}$ found decline in positive mood over the first 2 years following diagnosis, followed by an increase between the third and fifth years, with some subsequent stability. AMD patients were found to have poorer life satisfaction, greater stress, ${ }^{138}$ more emotional problems, greater social dysfunction ${ }^{139}$ and impaired activities of daily living over a 5 -year period ${ }^{140}$ than those without.

\section{Activities of daily living}

Nine studies investigating the effect of AMD on activities of daily living were identified. These included a total of 1279 participants with AMD. Seven of these were crosssectional, one was a case series and one was a case report. 
Studies $^{21} 141$ report that $39-45 \%$ of AMD patients require help with at least one activity of daily living. These studies and others ${ }^{78-80}$ suggest that between twice and eight times as many AMD patients require assistance with activities of daily living compared with those without. Severity of AMD is associated with these difficulties, ${ }^{18}$ which are unlikely to be experienced if visual function is unaffected, ${ }^{142}$ although night driving difficulties related to impaired scotopic sensitivity may occur while VA remains relatively good. ${ }^{143}$ Activities commonly affected include meal preparation, travelling, cleaning, grooming, shopping, going out, navigating steps and pavement curbs, noticing objects, hobbies, watching TV, reading, driving (especially night driving) and using low vision devices. ${ }^{18} 2188$ 143-145 In addition, ability to carry out activities requiring visual resolution, such as reading, can distinguish those who are capable of self-care only with those who are able to care for themselves and others. Likewise, ability to carry out household chores, such as preparing food, can distinguish those who are capable of self-care and those who are not. ${ }^{146}$

A case study ${ }^{147}$ of a patient with bilateral ring scotomas from AMD reported difficulties in 'several activities of daily living', in particular driving and following the ball when playing golf. The patient was reported to find compensatory scanning eye movements a useful way of keeping desired areas in focus.

\section{Qualitative data collection methods}

Eleven studies using interviews, focus groups and diaries to assess how AMD affects visual disability or QoL were identified. ${ }^{148-158}$ Their aims included illustrating 'living with AMD' and elucidating challenges caused by the condition. ${ }^{148-155}$ Others investigated factors associated with successful adaptation to AMD. ${ }^{156-158}$ The detailed results of these studies will be the subject of a subsequent report.

\section{Trends} representing the effects of AMD on QoL can be split
Our systematic review discovered that the literature

into four categories: wet AMD only; dry AMD only; both types investigated with a breakdown and both types investigated but without a breakdown or type not reported. We show that the number of QoL and visual ability papers published in these categories is increasing over time in figure 3 (before 1985 no studies had been published on the subject). This increase may simply be attributed to the increasing number of papers and journals published. Nevertheless, these studies make up a minute proportion of the body of literature on AMD as a whole; a PubMed search for articles with 'age-related macular degeneration' in their title published between 2010 and 2014 yields 2458 results, while only 47 papers $(<2 \%)$ published in this time were included in this systematic review.

\section{DISCUSSION}

Our review is timely. Although smaller scale systematic reviews have been published in this field, ${ }^{24-28}$ the most recent large-scale systematic reviews were published about 10 years ago. ${ }^{22} 23$ A more recent, non-systematic review published in $2013^{159}$ cited only 30 papers. Over half of the papers included in our study were published since these other large-scale systematic reviews were conducted.

Poku et $a l^{24}$ systematically reviewed utility values in patients with diabetic retinopathy, diabetic macular oedema and AMD in 2013 and concluded that according to the existing literature, AMD and diabetic retinopathy impact negatively on QoL, with most current research categorising by VA in patients' better-seeing eye. Tosh et $a l^{25}$ also conducted a systematic review of preference-based measures of QoL in visual disorders in 2012 with similar results. Pinquart $e t a l^{26}$ conducted a meta-analysis comparing psychological well-being in people with and without visual impairment. Results suggest that psychological well-being may be affected by having visual impairment, and in particular that those with AMD are more at risk for reduced psychological well-being than those with other causes of visual

Figure 3 Frequency of published papers over time grouped by AMD type reported. AMD, age-related macular degeneration.

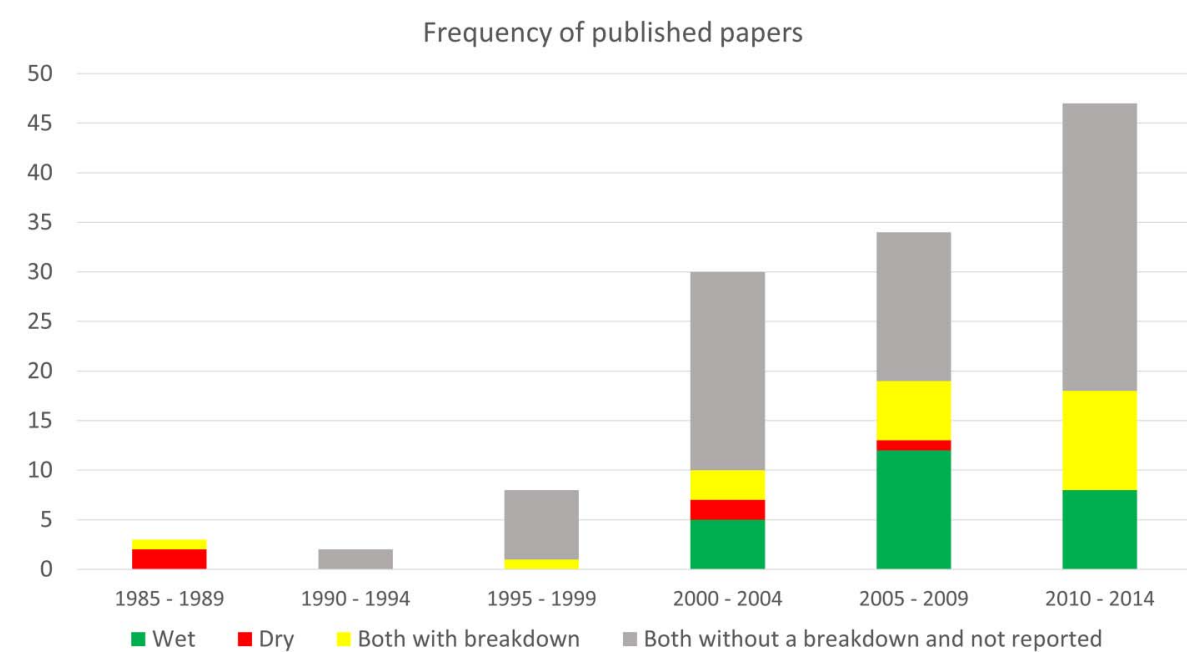


impairment. Depression and anxiety among those with AMD was systematically reviewed by Dawson et $a t^{27}$ in 2014. Depression was found to be more prevalent among those with AMD than those without. Furthermore, worse disease severity was associated with increased depressive symptoms. However, similar to the results of this systematic review, wide variability was found, perhaps due to differences in sample size and tools used in included studies. Their results suggest no relationship between AMD and anxiety. Qualitative studies concerned with the experience of AMD were systematically reviewed in 2012. ${ }^{28}$ Emerging themes centred on functional limitations, adaptation and independence, feelings about the future, interaction with health services, social engagement, disclosure and emotional impacts.

Our review is the first to integrate PROMs and performance-based studies assessing QoL and everyday visual function in AMD. The evidence presented in this study supports previous reviews' conclusions that AMD impacts negatively on people's lives. More is now understood about some of these areas of impact, for example, the relationship between AMD and falls, ${ }^{53} 54$ 78-80 101-104 and scene perception. ${ }^{61-69}$ AMD negatively affects tasks including mobility, face recognition, perception of scenes, computer use, meal preparation, shopping, cleaning, watching TV, reading, driving and, in some cases, self-care. A large number of studies have highlighted the difficulties people with AMD may have with mobility, particularly in dim lighting. ${ }^{48-51}$ Large-scale studies have reported invariably that many people with AMD self-report poor visual function; this worsens with AMD severity. ${ }^{16} 818384868790-939597$ There is limited evidence surrounding the issues people with AMD may have with using computers, due to the small sample sizes of the majority of studies identified. ${ }^{70-72} 75$

A number of domains within people's lives are affected by AMD: social, emotional and physical. Our systematic review highlights the need for eye-care providers to be aware of this research evidence, and to be able to manage these patients, whether it be referral for low vision rehabilitation or help from social or counselling services. Previous research ${ }^{114}{ }^{115}$ has shown that people without AMD, including eye-care providers, consistently underestimate the effect of the condition and it would be interesting to discover whether public perceptions are different now, with the advent of newsworthy potential new treatments. For example, a Google search for news articles about 'age-related macular degeneration treatment' published in 2004 generates three web pages of results, while a search for articles on the same topic published in 2014 generates 76 web pages.

We have also identified interesting trends in the publication of studies in this field (figure 3). There were no publications on QoL and visual disability in nAMD before 2000, and then there was a sudden increase; this is noteworthy and may be explained by the development of new treatments for nAMD around this time. ${ }^{160} 161$ These are likely to have resulted in increased interest in investigating QoL and functional impacts in order to assess clinical and cost-effectiveness outcomes of these new treatments. ${ }^{106}$ Few papers report the type of AMD investigated $(41 \%, n=51)$-worrying given the functional differences between the disease types, along with their differing time courses and treatments. ${ }^{27}$ It is, however, encouraging that more papers that include both types are now providing a breakdown between the two. Five and 25 papers focus solely on dry AMD and wet AMD respectively. This is disproportionate, given that dry AMD comprises $\sim 90 \%$ of diagnosed AMD cases. ${ }^{162}$ In addition, $74 \%$ of included studies ( $n=93$ ) do not report disease duration. As psychological and functional effects can change over the time course of the disease, this should be an important feature on which to report and comment.

Our results are supported by other studies, ${ }^{27} 28$ which discuss the lack of discrimination between wet and dry AMD in research. We spotlight this observation to be true in the majority of papers published in this field (figure 3). Critically, results from studies that did discriminate between the two indicate that QoL and visual function are affected in unique ways depending on disease type. For example, one study ${ }^{126}$ reported more nAMD patients than dry AMD patients suffering from depression. Another ${ }^{148}$ discussed the optimism that nAMD patients may feel receiving treatment and emphasised the sense of loss that those with dry AMD may suffer from due to lack of treatment. We think these findings are interesting, and more research addressing these differences is likely required. ${ }^{28}$

This study has limitations. First, only papers published in peer-reviewed journals were included. This is likely to have influenced the results found due to submission bias and/or publication bias. Second, the nature of this review meant that randomised control trials were excluded. Third, due to lack of translation resources, non-English language papers were excluded. Fourth, the impact of AMD on reading was not considered in this study because we felt this is a topic that is already very well reported on. For example, previous extensive reviews report reduced reading performance in $\mathrm{AMD}^{29} 30$ and subsequently reading is one of the most common valued activities to be lost as a result of AMD.$^{23}$ It is also worth noting that research in this field is not straightforward. For example, disentangling the effects of age alone from age-related eye disease is a challenge that often requires well-defined age-matched or age-related controls. Moreover, isolating the effect of AMD when elderly people have comorbidities is also a challenge. Still, using MMAT for our appraisal revealed most studies to have high levels of methodological quality.

\section{CONCLUSIONS}

Performance-based measures and PROMs have shown AMD to negatively affect QoL and visual disability; it 
affects many activities of daily living including, for example, mobility, driving, face recognition, scene perception and computer use. From earlier reviews, we know AMD also impacts critically on reading. Emotional impact can be severe. These impacts can differ over the time course of the disease, perhaps due to adaptation, and this should be acknowledged and investigated in future research. Future research in this field should also focus on delivering some of this research knowledge into the assessment of patients in clinical management and clinical trials. In other words, successful clinical management of AMD should not simply be about changes on a letter chart (eg, VA or CS) but must equate to correct decisions about intensifying treatment when patients are at risk of developing 'visual disability'. Furthermore, our review highlights a requirement to differentiate between types of AMD, especially as new disease-type specific treatments emerge for them.

Twitter Follow the Crabb Lab at @crabblab

Contributors All the authors contributed to study design. DJT and AEH screened abstracts and full-text articles for inclusion. DJT appraised study quality. Any disagreements or uncertainties during the screening and quality appraisal process were referred to DPC. DJT drafted the manuscript, which was reviewed, edited and approved by DPC and AMB.

Funding This work was supported by an unrestricted investigator initiated research grant from Roche Products, UK.

Competing interests None declared.

Patient consent No.

Provenance and peer review Not commissioned; externally peer reviewed.

Data sharing statement No additional data are available.

Open Access This is an Open Access article distributed in accordance with the Creative Commons Attribution Non Commercial (CC BY-NC 4.0) license, which permits others to distribute, remix, adapt, build upon this work noncommercially, and license their derivative works on different terms, provided the original work is properly cited and the use is non-commercial. See: http:// creativecommons.org/licenses/by-nc/4.0/

\section{REFERENCES}

1. Berdeaux GH, Nordmann JP, Colin E, et al. Vision-related quality of life in patients suffering from age-related macular degeneration. Am J Ophthalmol 2005;139:271-9.

2. Lamoureux EL, Pallant JF, Pesudovs K, et al. Assessing participation in daily living and the effectiveness of rehabilitation in age related macular degeneration patients using the impact of vision impairment scale. Ophthalmic Epidemiol 2008;15:105-13.

3. Owen CG, Jarrar Z, Wormald R, et al. The estimated prevalence and incidence of late stage age related macular degeneration in the UK. Br J Ophthalmol 2012;96:752-6.

4. Wong WL, Su X, Li X, et al. Global prevalence of age-related macular degeneration and disease burden projection for 2020 and 2040: a systematic review and meta-analysis. Lancet Global Health 2014;2:e106-16.

5. Bird AC, Bressler NM, Bressler SB, et al. An international classification and grading system for age-related maculopathy and age-related macular degeneration. Surv Ophthalmol 1995;39:367-74.

6. Ferris FL III, Wilkinson CP, Bird A, et al. Clinical classification of age-related macular degeneration. Ophthalmology 2013;120:844-51.

7. Marsiglia M, Boddu S, Bearelly S, et al. Association between geographic atrophy progression and reticular pseudodrusen in eyes with dry age-related macular degeneration. Invest Ophthalmol Vis Sci 2013;54:7362-9.

8. Felce D. Defining and applying the concept of quality of life. J Intellect Disabil Res 1997;41:126-35.
9. Hammell KW. Exploring quality of life following high spinal cord injury: a review and critique. Spinal Cord 2004;42:491-502.

10. Group W. Development of the WHOQOL: rationale and current status. Int J Ment Health 1994;23:24-56.

11. Harvey AS. Quality of life and the use of time theory and measurement. J Occup Sci 1993;1:27-30.

12. Scaffa ME, Van Slyke N, Brownson CA. American Occupational Therapy Association Commission on Practice. Occupational therapy services in the promotion of health and the prevention of disease and disability. Am J Occup Ther 2008;62: 694-703.

13. Patrick DL, Bergner M. Measurement of health status in the 1990s. Annu Rev Public Health 1990;11:165-83.

14. Guyatt GH, Feeny $\mathrm{DH}$, Patrick DL. Measuring health-related quality of life. Ann Intern Med 1993;118:622-9.

15. Patrick DL, Guyatt GH, Acquadro C. Chapter 17: Patient-reported outcomes. In: Cochrane Handbook for Systematic Reviews of Interventions Version 5.1.0 (updated March 2011). Julian PT Higgins and Sally Green. The Cochrane Collaboration, 2011. http:// www.cochrane-handbook.org

16. Clemons TE, Chew EY, Bressler SB, et al. National Eye Institute Visual Function Questionnaire in the Age-Related Eye Disease Study (AREDS): AREDS report no. 10. Arch Ophthalmol 2003;121:211-7.

17. Guyatt $\mathrm{GH}$, Bombardier C, Tugwell PX. Measuring disease-specific quality of life in clinical trials. CMAJ 1986;134:889-95.

18. Mangione CM, Gutierrez PR, Lowe G, et al. Influence of age-related maculopathy on visual functioning and health-related quality of life. Am J Ophthalmol 1999;128:45-53.

19. Friedman SM, Munoz B, Rubin GS, et al. Characteristics of discrepancies between self-reported visual function and measured Reading speed. Salisbury Eye Evaluation Project Team. Invest Ophthalmol Vis Sci 1999;40:858-64.

20. Guralnik JM, Branch LG, Cummings SR, et al. Physical performance measures in aging research. J Gerontol 1989;44:M141-M46.

21. Hochberg C, Maul E, Chan ES, et al. Association of vision loss in glaucoma and age-related macular degeneration with IADL disability. Invest Ophthalmol Vis Sci 2012;53:3201-6.

22. Berman K, Brodaty H. Psychosocial effects of age-related macular degeneration. Int Psychogeriatr 2006;18:415-28.

23. Mitchell J, Bradley C. Quality of life in age-related macular degeneration: a review of the literature. Health Qual Life Outcomes 2006;4

24. Poku E, Brazier J, Carlton J, et al. Health state utilities in patients with diabetic retinopathy, diabetic macular oedema and age-related macular degeneration: a systematic review. BMC Ophthalmol 2013;13:1-13.

25. Tosh J, Brazier J, Evans $P$, et al. A review of generic preference-based measures of health-related quality of life in visual disorders. Value Health 2012;15:118-27.

26. Pinquart M, Pfeiffer JP. Psychological well-being in visually impaired and unimpaired individuals: a meta-analysis. $\mathrm{Br} J$ Vis Impair 2011;29:27-45.

27. Dawson SR, Mallen CD, Gouldstone MB, et al. The prevalence of anxiety and depression in people with age-related macular degeneration: a systematic review of observational study data. BMC Ophthalmol 2014;14:78-78.

28. Bennion AE, Shaw RL, Gibson JM. What do we know about the experience of age related macular degeneration? A systematic review and meta-synthesis of qualitative research. Soc Sci Med 2012;75:976-85.

29. Kanonidou E. Reading performance and central field loss. Hippokratia 2011;15:103-8.

30. Neelam K, Nolan J, Chakravarthy U, et al. Psychophysical function in age-related maculopathy. Surv Ophthalmol 2009;54:167-210.

31. Pace R, Pluye P, Bartlett G, et al. Testing the reliability and efficiency of the pilot Mixed Methods Appraisal Tool (MMAT) for systematic mixed studies review. Int J Nurs Stud 2012;49:47-53.

32. Pieper $\mathrm{MJ}$, van Dalen-Kok $\mathrm{AH}$, Francke $\mathrm{AL}$, et al. Interventions targeting pain or behaviour in dementia: a systematic review. Ageing Res Rev 2013;12:1042-55.

33. Renzi C, Whitaker KL, Wardle J. Over-reassurance and undersupport after a 'false alarm': a systematic review of the impact on subsequent cancer symptom attribution and help seeking. BMJ Open 2015:5:e007002.

34. Peek ST, Wouters EJ, van Hoof J, et al. Factors influencing acceptance of technology for aging in place: a systematic review. Int J Med Inform 2014;83:235-48.

35. Popescu ML, Boisjoly $\mathrm{H}$, Schmaltz $\mathrm{H}$, et al. Age-related eye disease and mobility limitations in older adults. Invest Ophthalmol Vis Sci 2011;52:7168-74. 
36. Elliott DB, Patla AE, Flanagan JG, et al. The Waterloo Vision and Mobility Study: postural control strategies in subjects with ARM Ophthalmic Physiol Opt 1995;15:553-9.

37. Kotecha A, Chopra R, Fahy RTA, et al. Dual tasking and balance in those with central and peripheral vision loss. Invest Ophthalmol Vis Sci 2013;54:5408-15.

38. Wood JM, Lacherez PF, Black AA, et al. Postural stability and gait among older adults with age-related maculopathy. Invest Ophthalmol Vis Sci 2009;50:482-7.

39. Hassan SE, Lovie-Kitchin JE, Woods RL. Vision and mobility performance of subjects with age-related macular degeneration. Optom Vis Sci 2002;79:697-707.

40. Geruschat DR, Fujiwara K, Wall Emerson RS. Traffic gap detection for pedestrians with low vision. Optom Vis Sci 2011;88(2):208-16.

41. Geruschat DR, Hassan SE, Turano KA, et al. Gaze behavior of the visually impaired during street crossing. Optom Vis Sci 2006;83:550-8.

42. Hassan SE, Geruschat DR, Turano KA. Head movements while crossing streets: effect of vision impairment. Optom Vis $\mathrm{Sci}$ 2005;82:18-26.

43. Hassan SE, Snyder BD. Street-crossing decision-making: a comparison between patients with age-related macular degeneration and normal vision. Invest Ophthalmol Vis Sci 2012:53:6137-44.

44. Curriero FC, Pinchoff J, Van Landingham SW, et al. Alteration of travel patterns with vision loss from glaucoma and macular degeneration. JAMA Ophthalmol 2013;131:1420-6.

45. Lovie-Kitchin JE, Brown B. Reaction time in age-related maculopathy. Am J Optom Physiol Opt 1986;63:366-71.

46. Szlyk JP, Pizzimenti CE, Fishman GA, et al. A comparison of driving in older subjects with and without age-related macular degeneration. Arch Ophthalmol 1995;113:1033-40.

47. Spaulding SJ, Patla AE, Elliott DB, et al. Waterloo vision and mobility study: gait adaptations to altered surfaces in individuals with age-related maculopathy. Optom Vis Sci 1994;71:770-7.

48. Spaulding SJ, Patla AE, Flanagan J, et al. Waterloo Vision and Mobility Study: Normal gait characteristics during dark and light adaptation in individuals with age-related maculopathy. Gait Posture 1995;3:227-35.

49. Alexander MS, Lajoie K, Neima DR, et al. Effect of ambient light and age-related macular degeneration on precision walking. Optom Vis Sci 2014:91:990-9.

50. Alexander MS, Lajoie K, Neima DR, et al. Effects of age-related macular degeneration and ambient light on curb negotiation. Optom Vis Sci 2014:91:975-89.

51. Brown B, Brabyn L, Welch L. Contribution of vision variables to mobility in age-related maculopathy patients. Am J Optom Physiol Opt 1986;63:733-9.

52. Kuyk T, Elliott JL. Visual factors and mobility in persons with age-related macular degeneration. J Rehabil Res Dev 1999;36:303-12.

53. Szabo SM, Janssen PA, Khan K, et al. Older women with age-related macular degeneration have a greater risk of falls: a physiological profile assessment study. J Am Geriatr Soc 2008;56:800-7

54. Wang MY, Rousseau J, Boisjoly $\mathrm{H}$, et al. Activity limitation due to a fear of falling in older adults with eye disease. Invest Ophthalmol Vis Sci 2012:53:7967-72.

55. Aspinall PA, Borooah S, Al Alouch C, et al. Gaze and pupil changes during navigation in age-related macular degeneration. $\mathrm{Br}$ $J$ Ophthalmol 2014:98:1393-7.

56. Alexander MF, Maguire MG, Lietman TM, et al. Assessment of visual function in patients with age-related macular degeneration and low visual acuity. Arch Ophthalmol 1988;106:1543-7.

57. Boucart M, Dinon JF, Despretz $\mathrm{P}$, et al. Recognition of facial emotion in low vision: a flexible usage of facial features. Vis Neurosci 2008;25:603-9.

58. Bullimore MA, Bailey IL, Wacker RT. Face recognition in age-related maculopathy. Invest Ophthalmol Vis Sci 1991;32:2020-9.

59. Seiple W, Rosen RB, Garcia PM. Abnormal fixation in individuals with age-related macular degeneration when viewing an image of a face. Optom Vis Sci 2013;90:45-56.

60. Tejeria L, Harper RA, Artes $\mathrm{PH}$, et al. Face recognition in age related macular degeneration: perceived disability, measured disability, and performance with a bioptic device. Br J Ophthalmol 2002;86:1019-26.

61. Boucart M, Despretz P, Hladiuk K, et al. Does context or color improve object recognition in patients with low vision? Vis Neurosci 2008;25:685-91.
62. Tran THC, Guyader N, Guerin A, et al. Figure ground discrimination in age-related macular degeneration. Invest Ophthalmol Vis Sci 2011;52:1655-60.

63. Boucart M, Moroni C, Szaffarczyk S, et al. Implicit processing of scene context in macular degeneration. Invest Ophthalmol Vis Sci 2013;54:1950-7

64. Musel B, Hera R, Chokron S, et al. Residual abilities in age-related macular degeneration to process spatial frequencies during natural scene categorization. Vis Neurosci 2011;28:529-41.

65. Bordier C, Petra J, Dauxerre C, et al. Influence of background on image recognition in normal vision and age-related macular degeneration. Ophthalmic Physiol Opt 2011;31:203-15.

66. Tran TH, Despretz P, Boucart M. Scene perception in age-related macular degeneration: the effect of contrast. Optom Vis $\mathrm{Sci}$ 2012;89:419-25

67. Tran THC, Rambaud C, Despretz P, et al. Scene perception in age-related macular degeneration. Invest Ophthalmol Vis Sci 2010;51:6868-74.

68. Thibaut M, Tran THC, Szaffarczyk S, et al. The contribution of central and peripheral vision in scene categorization: a study on people with central vision loss. Vision Res 2014:98:46-53.

69. Tran TH, Despretz P, Boucart M. Space representation in age-related macular degeneration. Optom Vis Sci 2014;91:1012-20.

70. Jacko JA, Barreto AB, Chu JYM, et al. Macular degeneration and visual search: what we can learn from eye movement analysis. Proc Hum Factors Ergon Soc Annu Meet 2000;44:116-9

71. Jacko JA, Barreto AB, Scott IU, et al. Macular degeneration and visual icon use: deriving guidelines for improved access. Univers Access Inf Soc 2002;1:197-206.

72. Jacko JA, Moloney KP, Kongnakorn T, et al. Multimodal feedback as a solution to ocular disease-based user performance decrements in the absence of functional visual loss. Int J Hum-Comput Interact 2005;18:183-218.

73. Scott IU, Feuer WJ, Jacko JA. Impact of visual function on computer task accuracy and reaction time in a cohort of patients with age-related macular degeneration. Am J Ophthalmol 2002;133:350-7

74. Scott IU, Feuer WJ, Jacko JA. Impact of graphical user interface screen features on computer task accuracy and speed in a cohor of patients with age-related macular degeneration. Am J Ophthalmol 2002;134:857-62.

75. Jacko JA, Scott IU, Barreto BA, et al. Iconic visual search strategies: a comparison of computer users with AMD versus computer users with normal vision. Proceedings of the Ninth International Conference on Human-Computer Interaction. 2001

76. Timberlake GT, Omoscharka E, Quaney BM, et al. Effect of bilateral macular scotomas from age-related macular degeneration on reach-to-grasp hand movement. Invest Ophthalmol Vis Sci 2011;52:2540-50.

77. Timberlake GT, Bothwell RJ, Moyer K. Handwriting with a preferred retinal locus for AMD with scotomas. Optom Vis Sci 2013;90:455-65.

78. Cruess A, Zlateva G, Xu X, et al. Burden of illness of neovascular age-related macular degeneration in Canada. Can J Ophthalmol 2007:42:836-43

79. Soubrane G, Cruess A, Lotery A, et al. Burden and health care resource utilization in neovascular age-related macular degeneration: findings of a multicountry study. Arch Ophthalmol 2007;125:1249-54.

80. Lotery A, Xu X, Zlatava G, et al. Burden of illness, visual impairment and health resource utilisation of patients with neovascular age-related macular degeneration: results from the UK cohort of a five-country cross-sectional study. $\mathrm{Br} J$ Ophthalmol 2007;91:1303-7

81. Lin JC, Yu JH. Assessment of quality of life among Taiwanese patients with visual impairment. J Formos Med Assoc 2012;111:572-9.

82. Lopez-Miguel A, Coco-Martin MB, Martinez-Fernandez R, et al. Patient-reported outcomes in Spanish patients diagnosed with bilateral age-related macular degeneration. Ophthalmologica 2013;230:69-75

83. Ruiz-Moreno JM, Coco RM, Garcia-Arumi J, et al. Burden of illness of bilateral neovascular age-related macular degeneration in Spain. Curr Med Res Opin 2008;24:2103-11.

84. Seland JH, Vingerling JR, Augood CA, et al. Visual impairment and quality of life in the older European Population, the EUREYE study. Acta Ophthalmol 2011;89:608-13.

85. Cahill MT, Banks AD, Stinnett SS, et al. Vision-related quality of life in patients with bilateral severe age-related macular degeneration. Ophthalmology 2005;112:152-8. 
86. Siaudvytyte L, Mitkute D, Balciuniene J. Quality of life in patients with age-related macular degeneration. Medicina (Lithuania) 2012;48:109-11

87. Lamoureux EL, Mitchell P, Rees G, et al. Impact of early and late age-related macular degeneration on vision-specific functioning. Br J Ophthalmol 2011;95:666-70.

88. Hassell JB, Lamoureux EL, Keeffe JE. Impact of age related macular degeneration on quality of life. $\mathrm{Br} J$ Ophthalmol 2006;90:593-6.

89. Chia EM, Wang JJ, Rochtchina E, et al. Impact of bilateral visual impairment on health-related quality of life: the Blue Mountains Eye Study. Invest Ophthalmol Vis Sci 2004;45:71-6.

90. Esteban JJ, Martínez MS, Navalón PG, et al. Visual impairment and quality of life: gender differences in the elderly in Cuenca, Spain. Qual Life Res 2008;17:37-45.

91. Coleman AL, Yu F, Ensrud KE, et al. Impact of age-related macular degeneration on vision-specific quality of life: follow-up from the 10 -year and 15-year visits of the study of osteoporotic fractures. Am J Ophthalmol 2010;150:683-91.

92. Maguire M. Baseline characteristics, the 25-Item National Eye Institute Visual Functioning Questionnaire, and their associations in the Complications of Age-Related Macular Degeneration Prevention Trial (CAPT). Ophthalmology 2004;111:1307-16.

93. Sahel JA, Bandello F, Augustin A, et al. Health-related quality of life and utility in patients with age-related macular degeneration. Arch Ophthalmol 2007;125:945-51.

94. Dong LM. Health- and vision-related quality of life among patients with choroidal neovascularization secondary to age-related macular degeneration at enrollment in randomized trials of submacular surgery: SST report no. 4. Am J Ophthalmol 2004;138:91-108.

95. Marback RF, Maia OOJr, Morais FB, et al. Quality of life in patients with age-related macular degeneration with monocular and binocular legal blindness. Clinics (Sao Paulo) 2007;62:573-8

96. Williams RA, Brody BL, Thomas RG, et al. The psychosocial impact of macular degeneration. Arch Ophthalmol 1998;116:514-20.

97. Rovner BW, Casten RJ, Hegel MT, et al. Personality and functional vision in older adults with age-related macular degeneration. J Visual Impair Blin 2014;108:187-99.

98. McGwin GJr, Mitchell B, Searcey K, et al. Examining the association between age-related macular degeneration and motor vehicle collision involvement: a retrospective cohort study. $\mathrm{Br}$ J Ophthalmol 2013;97:1173-6.

99. Decarlo DK, Scilley K, Wells J, et al. Driving habits and health-related quality of life in patients with age-related maculopathy. Optom Vis Sci 2003;80:207-13.

100. Sengupta S, Van Landingham SW, Solomon SD, et al. Driving habits in older patients with central vision loss. Ophthalmology 2014;121:727-32.

101. Wood JM, Lacherez $P$, Black AA, et al. Risk of falls, injurious falls, and other injuries resulting from visual impairment among older adults with age-related macular degeneration. Invest Ophthalmol Vis Sci 2011:52:5088-92.

102. Szabo SM, Janssen PA, Khan K, et al. Neovascular AMD: an overlooked risk factor for injurious falls. Osteoporos Int 2010;21:855-62.

103. van Landingham SW, Massof RW, Chan E, et al. Fear of falling in age-related macular degeneration. BMC Ophthalmo 2014;14:10-10.

104. Popescu ML, Boisjoly $\mathrm{H}$, Schmaltz $\mathrm{H}$, et al. Explaining the relationship between three eye diseases and depressive symptoms in older adults. Invest Ophthalmol Vis Sci 2012;53:2308-13.

105. Brown GC, Sharma S, Brown MM, et al. Utility values and age-related macular degeneration. Arch Ophthalmol 2000;118:47-51

106. Espallargues M, Czoski-Murray CJ, Bansback NJ, et al. The impac of age-related macular degeneration on health status utility values. Invest Ophthalmol Vis Sci 2005;46:4016-23.

107. Yanagi Y, Ueta T, Obata R, et al. Utility values in Japanese patients with exudative age-related macular degeneration. Jpn J Ophthalmol 2011;55:35-8.

108. Bass EB, Marsh MJ, Mangione CM, et al. Patients' perceptions of the value of current vision: assessment of preference values among patients with subfoveal choroidal neovascularization-The Submacular Surgery Trials Vision Preference Value Scale: SST Report No. 6. Arch Ophthalmol 2004;122:1856-67.

109. Brown MM, Brown GC, Sharma S, et al. Health care economic analyses and value-based medicine. Surv Ophthalmol 2003;48:204-23.

110. Kymes SM, Lee BS. Preference-based quality of life measures in people with visual impairment. Optom Vis Sci 2007;84:809-16.
111. Brown MM, Brown GC, Sharma S, et al. Quality of life with visual acuity loss from diabetic retinopathy and age-related macular degeneration. Arch Ophthalmol 2002;120:481-4

112. Bansback N, Czoski-Murray C, Carlton J, et al. Determinants of health related quality of life and health state utility in patients with age related macular degeneration: the association of contrast sensitivity and visual acuity. Qual Life Res 2007:16:533-43.

113. Butt T, Dunbar HMP, Morris S, et al. Patient and public preferences for health states associated with AMD. Optom Vis $\mathrm{Sci}$ 2013;90:855-60.

114. Stein JD, Brown MM, Brown GC, et al. Quality of life with macular degeneration: perceptions of patients, clinicians, and community members. Br J Ophthalmol 2003;87:8-12.

115. Brown GC, Brown MM, Sharma S. Difference between ophthalmologists' and patients' perceptions of quality of life associated with age-related macular degeneration. Can J Ophthalmol 2000;35:127-33.

116. Brody BL, Gamst AC, Williams RA, et al. Depression, visual acuity, comorbidity, and disability associated with age-related macular degeneration. Ophthalmology 2001;108:1893-900.

117. Eramudugolla R, Wood J, Anstey KJ. Co-morbidity of depression and anxiety in common age-related eye diseases: a population-based study of 662 adults. Front Aging Neurosci 2013;5:56

118. Mathew RS, Delbaere K, Lord SR, et al. Depressive symptoms and quality of life in people with age-related macular degeneration. Ophthalmic Physiol Opt 2011;31:375-80.

119. Jivraj J, Jivraj I, Tennant M, et al. Prevalence and impact of depressive symptoms in patients with age-related macular degeneration. Can J Ophthalmol 2013;48:269-73.

120. Sun C, Tikellis G, Klein R, et al. Depressive symptoms and age-related macular degeneration in older people: the cardiovascular health study. Ophthalmic Epidemiol 2007;14:127-33.

121. Augustin A, Sahel JA, Bandello F, et al. Anxiety and depression prevalence rates in age-related macular degeneration. Invest Ophthalmol Vis Sci 2007;48:1498-503.

122. Rovner BW, Casten RJ. Neuroticism predicts depression and disability in age-related macular degeneration. J Am Geriatr Soc 2001;49:1097-100.

123. Rovner BW, Casten RJ. Activity loss and depression in age-related macular degeneration. Am J Geriatr Psychiatry 2002;10:305-10.

124. Rovner BW, Casten RJ, Tasman WS. Effect of depression on vision function in age-related macular degeneration. Arch Ophthalmol 2002;120:1041-4.

125. Rovner BW, Casten RJ, Hegel MT, et al. Minimal depression and vision function in age-related macular degeneration. Ophthalmology 2006;113:1743-7.

126. Banerjee A, Kumar S, Kulhara P, et al. Prevalence of depression and its effect on disability in patients with age-related macular degeneration. Indian J Ophthalmol 2008:56:469-74.

127. Casten RJ, Rovner BW, Edmonds SE. The impact of depression in older adults with age-related macular degeneration. $J$ Vis Impair Blind 2002:96:399-406.

128. Tolman J, Hill RD, Kleinschmidt JJ, et al. Psychosocial adaptation to visual impairment and its relationship to depressive affect in older adults with age-related macular degeneration. Gerontologist 2005;45:747-53.

129. Johnson T, Rovner B, Haller J. Suicide and visual loss: a case report reflecting the need for recognition and management in ophthalmological settings. Semin Ophthalmol 2014;29:202-4

130. Heckhausen J, Schulz R. A life-span theory of control. Psychol Rev 1995;102:284-304.

131. Wahl H-W, Schilling O, Becker S, et al. A German research program on the psychosocial adaptation to age-related vision impairment: recent findings based on a control theory approach Eur Psychol 2003;8:168-77.

132. Wahl HW, Becker S, Burmedi $D$, et al. The role of primary and secondary control in adaptation to age-related vision loss: a study of older adults with macular degeneration. Psychol Aging 2004;19:235-9.

133. Wahl HW, Schilling O, Becker S. Age-related macular degeneration and change in psychological control: role of time since diagnosis and functional ability. J Gerontol B Psychol Sci Soc Sci 2007;62: P90-7.

134. Wahl HW, Schilling O, Becker S. Psychosocial adaptation to age-related macular degeneration: the role of control beliefs. Int Congr Ser 2005;1282:326-30.

135. Schilling OK, Wahl HW, Boerner K, et al. Change in psychological control in visually impaired older adults over 2 years: role of functional ability and depressed mood. J Gerontol B Psychol Sci Soc Sci 2013;68:750-61. 
136. Rovner BW, Casten RJ, Massof RW, et al. Psychological and cognitive determinants of vision function in age-related macular degeneration. Arch Ophthalmol 2011;129:885-90.

137. Schilling OK, Wahl HW. Modeling late-life adaptation in affective well-being under a severe chronic health condition: the case of age-related macular degeneration. Psychol Aging 2006;21:703-14

138. Davis C, Lovie-Kitchin J, Thompson B. Psychosocial adjustment to age-related macular degeneration. $J$ Vis Impair Blind 1995;89:16-27.

139. Cavar I, Lovric S, Vukojevic M, et al. Metabolic risk factors, coping with stress, and psychological well-being in patients with age-related macular degeneration. Acta Clin Croat 2014;53:79-87.

140. Gopinath B, Liew G, Burlutsky G, et al. Age-related macular degeneration and 5-year incidence of impaired activities of daily living. Maturitas 2014;77:263-6.

141. Mathew R, Delbaere K, Madigan M, et al. Depressive symptoms and quality of life in people with age-related macular degeneration. Clin Experiment Ophthalmol 2011;39:82

142. Knudtson MD, Klein BEK, Klein R, et al. Age-related eye disease, quality of life, and functional activity. Arch Ophthalmol 2005;123:807-14

143. Scilley K, Jackson GR, Cideciyan AV, et al. Early age-related maculopathy and self-reported visual difficulty in daily life. Ophthalmology 2002;109:1235-42.

144. Ivanoff SD, Sonn U, Lundgren-Lindqvist B, et al. Disability in daily life activities and visual impairment: a population study of 85-year-old people living at home. Scand J Occup Ther 2000;7:148-55.

145. Backman $\mathrm{H}$, Williams $\mathrm{R}$. Living with age-related macular degeneration. J Vis Impair Blind 2002;96:345-8.

146. Stevenson MR, Hart PM, Montgomery AM, et al. Reduced vision in older adults with age related macular degeneration interferes with ability to care for self and impairs role as carer. $\mathrm{Br} J$ Ophthalmol 2004:88:1125-30.

147. Fletcher DC, Schuchard RA, Walker JP, et al. Patient with macular disease, good visual acuity, and central visual field disruption and significant difficulties with activities of daily living. $J$ Vis Impair Blind 2008;102:656-88.

148. McCloud C, Khadka J, Gilhotra JS, et al. Divergence in the lived experience of people with macular degeneration. Optom Vis Sci 2014;91:966-74.
149. Wong EYH, Guymer RH, Hassell JB, et al. The experience of age-related macular degeneration. J Vis Impair Blind 2004;98:629-40

150. Burton AE, Shaw RL, Gibson JM. Living together with age-related macular degeneration: an interpretative phenomenological analysis of sense-making within a dyadic relationship. J Health Psychol 2015;20:1285-95.

151. Moore LW. Severe visual impairment in older women. West J Nurs Res 2000;22:571-88. Discussion 88-95.

152. Moore LW, Miller M. Older men's experiences of living with severe visual impairment. J Adv Nurs 2003;43:10-8.

153. Moore LW, Miller M. Driving strategies used by older adults with macular degeneration: assessing the risks. Appl Nurs Res 2005;18:110-6.

154. Owsley C, McGwin Jr G, Scilley K, et al. Focus groups with persons who have age-related macular degeneration: emotional issues. Rehabil Psychol 2006;51:23-9.

155. Cimarolli VR, Boerner K, Brennan-Ing M, et al. Challenges faced by older adults with vision loss: a qualitative study with implications for rehabilitation. Clin Rehabil 2012;26:748-57.

156. Stanford $\mathrm{P}$, Waterman $\mathrm{H}$, Russell WB, et al. Psychosocial adjustment in age related macular degeneration. $\mathrm{Br} J$ Vis Impair 2009;27: 129-46.

157. Kleinschmidt JJ. Older adults' perspectives on their successful adjustment to vision loss. J Vis Impair Blind 1999;93:69-81.

158. Smith TM. Adaptation to low vision caused by age-related macular degeneration: a case study. J Vis Impair Blind 2008;102 725-30.

159. Yuzawa M, Fujita K, Tanaka E, et al. Assessing quality of life in the treatment of patients with age-related macular degeneration: clinica research findings and recommendations for clinical practice. Clin Ophthalmol 2013;7:1325-32.

160. Verteporfin Roundtable 2000 and 2001 Participants, et al. Guidelines for using verteporfin (visudyne) in photodynamic therapy to treat choroidal neovascularization due to age-related macular degeneration and other causes. Retina 2002;22:6-18.

161. Kim LA, D'Amore PA. A brief history of anti-VEGF for the treatment of ocular angiogenesis. Am J Pathol 2012;181:376-9.

162. Chen Y, Vuong LN, Liu J, et al. Three-dimensional ultrahigh resolution optical coherence tomography imaging of age-related macular degeneration. Opt Express 2009;17:4046-60. 